\title{
Residual Stress Relaxation in Welded Steel Joints - an Experimentally-based Model
}

\author{
Jonas Hensel ${ }^{1, a^{*}}$, Thomas Nitschke-Pagel ${ }^{1, b}$ and Klaus Dilger ${ }^{1, c}$ \\ ${ }^{1}$ Institute of Joining and Welding, TU Braunschweig, Langer Kamp 8, 38106 Braunschweig, \\ Germany \\ aj.hensel@tu-braunschweig.de, bt.pagel@tu-braunschweig.de, k.dilger@tu-braunschweig.de \\ * corresponding author
}

Keywords: Residual Stresses, Residual Stress Relaxation, Welding, Fatigue, Steel

\begin{abstract}
Residual stresses may affect the fatigue strength of welded components significantly. Structural design concepts for fatigue loaded welds do not account for real residual stress conditions but rather generally estimate high tensile residual stresses. The assumption of high tensile residual stresses in current engineering practice is resulting in over-conservative designs. The consideration of real residual stress conditions in the design process is one of the major objectives in current research on structural engineering. In order to achieve this objective, one must be able to describe the residual stress generation due to manufacturing and the relaxation of residual stresses during component life time. However, nowadays it is not practical to describe the relaxation process by means of numerical or analytical methods. This work describes an experimentally-based model for the estimation of the stabilized residual stresses in welded steels. The model is capable of describing residual stress relaxation depending on the initial residual stresses, the load magnitudes and the material strength. The model is based on XRD residual stress measurements during the fatigue life of typical welded joints. The samples used here are longitudinal fillet welded gussets made from low-carbon highstrength construction steels S355NL (yield strength $360 \mathrm{MPa}$ ) and S960QL (yield strength $960 \mathrm{MPa}$ ). Finally, the model is extended to butt welded joints using experimental data from the literature.
\end{abstract}

\section{Introduction}

Residual stress effects in fatigue design of welded steels. The fatigue strength of welded components is of major concern for component safety and durability. In engineering practice fatigue strength is mainly examined by means of the nominal stress approach. Speaking generally this method compares expected fatigue loads in the net section of the weld details to a reference design $\mathrm{S}-\mathrm{N}$ curve $[1,2]$. The reference S-N curves are provided by technical standards or design recommendations and are specific to certain weld details such as un-welded base metal, butt welds, cruciform joints or longitudinal fillet welded gussets. Each design S-N curves relates the expected fatigue load to a specific number of load cycles until this load can be born by the component without

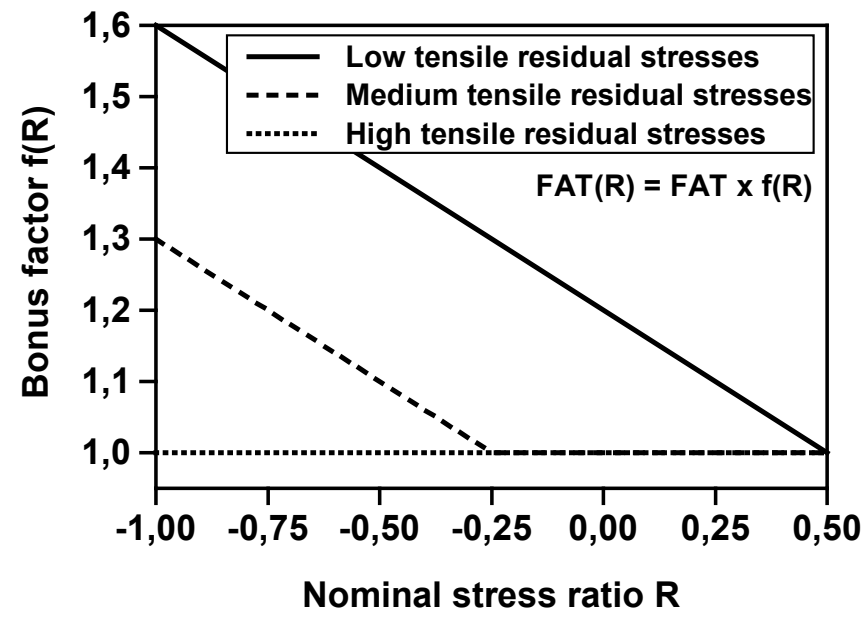

Fig. 1 Effect of tensile mean stresses on the design fatigue strength for welded steels in dependence of the residual stress conditions [1] 
failure. Codes for structural design assume conservatively high tensile residual stresses resulting from the entire manufacturing process including welding and mounting are present [3]. This results in mean stress independency of the design S-N curves if real residual stress conditions are unknown.

However, post-weld treatment methods such as thermal stress relieve are capable of reducing residual stresses leading to an increase of fatigue strength. Thus the IIW-recommendations for fatigue design of welded structures allow for the consideration of the mean stress effect in case of proven low or medium tensile residual stresses. This can be executed by means of a bonus factor manipulating the design fatigue strength of a weld detail based on the applied stress ratio, Fig. 1. One of the major uncertainties is how users of the design code can judge whether the proven residual stresses in the component of interest are "high" or "low". Consequently residual stresses and their effects are often conservatively over-estimated leading to un-economical structural design.

The reference fatigue strengths for different weld details given by above mentioned design codes are usually based on experimental fatigue testing of small scale specimens with typically low residual stresses. The lack of residual stresses on the laboratory scale is compensated by testing at high tensile mean stresses respectively positive stress ratios $\mathrm{R}=\sigma_{\min } / \sigma_{\max }=0.5$ or $\mathrm{R}=0[1,2]$. The applied mean stresses are supposed to reflect tensile residual stresses in large scale components conservatively.

In terms of fatigue design these codes equate residual stresses and load mean stresses, although residual stresses may be subject to change during component lifetime. Thus residual stresses may be assumed too high leading to the fatigue resistance being under-estimated accordingly. This hidden potential of fatigue strength could be used in the future in order to accomplish a more economical design of welded structures.

Residual stress relaxation in cyclically loaded welded steels. Speaking generally, residual stresses in steels are limited by the yield strength of the material. Residual stresses are hence degraded under mechanical loading as far as the sum of residual stresses and load stresses theoretically exceeds the yield strength. In case of fatigue loaded welds with high tensile residual stresses the material's yield strength is equal to the maximum stress of the fatigue loading [3]. It was pointed out that residual stresses far below the yield strength can have severe influence on the fatigue strength especially in case of high strength steels because of their stability under service loading [4].

The general mechanisms of residual stress relaxation were described earlier and classified in four groups [5]. These four cases illustrate residual stress relaxation according to the static yield strength, the cyclic yield strength and according to combinations of both, Fig. 2. Case one describes the situation of stable residual stresses which can be observed if both residual stresses and maximum load stresses are low. Case two describes continuous residual stress relaxation according to the cyclic yield strength. Here residual stress relaxation occurs due to cyclic softening of the material. Cases three and four describe residual stress relaxation according to the static yield strength during initial loading. Additionally case four includes cyclic softening which leads to continuous cyclic residual stress degradation as well. However, residual stress degradation in welded construction steels is usually governed by case three. Case four applies to welded and heat treated high strength steels with martensite and bainite microstructure (respectively the heat affected zone of ferritic steels) but is usually of second order compared to case three [6,7]. Further it was shown that the combined static and cyclic residual stress relaxation is approximately finished after $\mathrm{N}=10,000$ load cycles [6]. It has been shown to be practical to consider the maximum respectively minimum

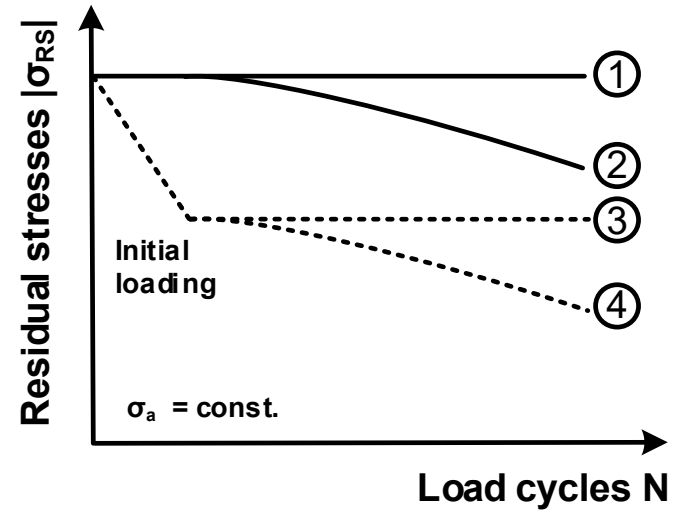

Fig. 2 Residual stress degradation due to cyclic loading according to Vöhringer [5] 
load stress during a certain load cycle for the consideration of tensile and compressive residual stresses respectively. Additionally residual stresses are mostly considered in the loading direction perpendicular to the fatigue crack growth direction. All results from residual stress measurements shown here refer to the residual stress component in the loading direction.

Residual stress relaxation in welds can be observed due to stress concentration at weld notches or simply due to high maximum stresses. One example for such behavior of residual stresses in buttwelded joints under static and cyclic loading is given in Fig. 3 [8]. Samples were loaded incrementally statically and cyclically and residual stresses were determined after each load step. Static loading led to residual stress degradation in both steel grades according to case three described by Vöhringer.

Cyclic constant amplitude loading until $\mathrm{N}=10,000$ load cycles led to higher residual stress degradation. Residual stresses after $\mathrm{N}=10,000$ load cycles were degraded depending on the magnitude of the initial residual stresses and the maximum load stresses. Both materials S355J2 and S690Q showed similar behavior in terms of cyclic residual stress relaxation. Not shown here is that residual stresses had stabilized at this stage of cyclic loading.

Vöhringer's case three applies only partially to the cyclically loaded butt-welds due to cyclic plasticity effects at the weld toe. The increase of residual stress relaxation under cyclic loading is explained by the application of full load cycles (compared to single tension loading in the static load case) and due to cyclic softening of the material. However, in engineering practice it is normally not practical to establish the cyclic mechanical properties of a certain material. Consequently the designers demand for a model that is capable of estimating the stabilized residual stresses as a function of the base material strength and the applied load stresses. Although residual stress relaxation in general is quite well understood, more experimental data is needed to derive such an engineering model.
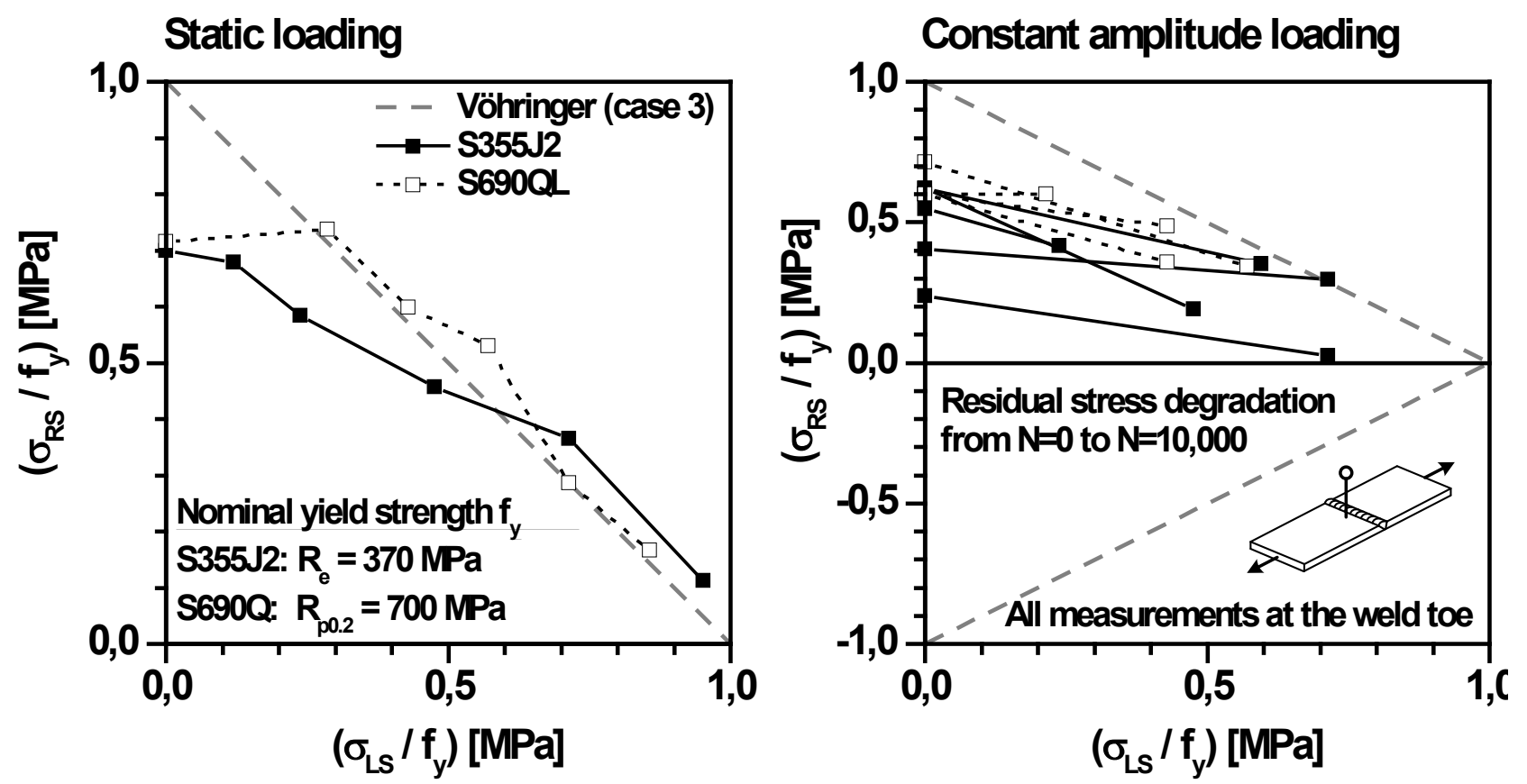

Fig. 3 Static and cyclic residual stress relaxation at the weld toe of butt-welded steel joints [8]. Nominal load stresses $\sigma_{L S}$ reflect the maximum applied stress in the net section (in case of cyclic loading: Mean stress plus stress amplitude) 


\section{Additional experimental investigations on residual stress relaxation in welded steels}

Linear welds such as butt-welds show relatively low stress concentration while another group of welded joints show rather high stress concentration. Accordingly these weld types are characterized by higher plasticity effects at the weld notch due to local load stress increase. One of such weld types with higher stress concentration ( $\mathrm{kt} \approx 3$ at a notch radius $\rho_{\mathrm{k}}=1 \mathrm{~mm}$ and sheet thickness $\mathrm{t}=10 \mathrm{~mm}$ ) is the longitudinal fillet welded gusset with relatively high tensile residual stresses in the as-welded condition, Fig. 4. This sample type was used here for further investigations on residual stress relaxation.

Samples were made from low-alloyed construction steels with yield strengths of $\mathrm{f}_{\mathrm{y}}=360 \mathrm{MPa}$ $(\mathrm{S} 355 \mathrm{NL})$ and $\mathrm{f}_{\mathrm{y}}=1000 \mathrm{MPa}(\mathrm{S} 960 \mathrm{QL})$. The one-layered fillet welds were produced using general metal arc (GMA) welding with solid wire electrodes of matching strengths. The welding parameters were chosen in order to ensure high safety against cold cracking. The high strength material S960QL was pre-heated to $100^{\circ} \mathrm{C}$ accordingly.

Residual stresses were determined by means of $\mathrm{X}$ ray diffraction (XRD) and the $\sin ^{2} \Psi$-method. Diffraction lines of the $\{211\}$-patterns were obtained with Cr-radiation. The irradiated area was controlled using a collimator with a diameter of $2 \mathrm{~mm}$. Residual stresses were measured at the location of crack initiation under fatigue loading and determined initially "as-welded" as well as after repeated cyclic loading. As discussed above residual stresses were measured after 10,000 load cycles to establish the stabilized residual stresses. The initial residual stresses were controlled by heat input and post-weld treatment methods and samples with both compressive and tensile residual stresses at the weld notch were chosen for these

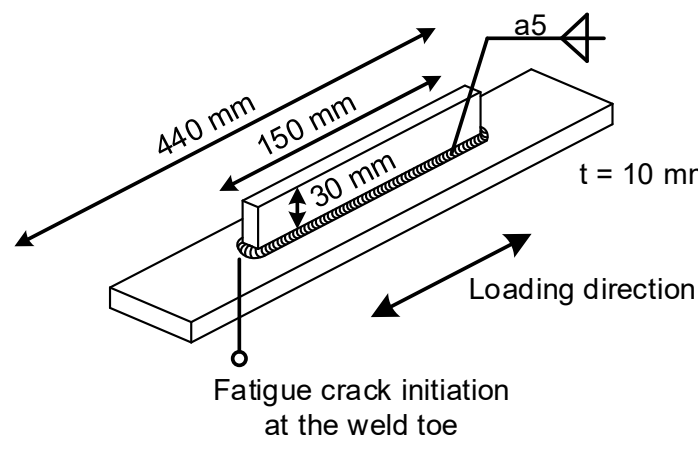

Fig. 4 Specimen type used: Longitudinal fillet welded gusset investigations.

\section{Residual stress relaxation}

Samples of both steel grades were loaded statically in tension. The load was increased incrementally and residual stresses were measured after each load step on the unclamped samples. It can be seen from Fig. 5 that residual stresses in S355N were degraded continously although the load stresses were comparably small. Specimens made from S960Q showed a similar tendency up to $70 \%$ of the yield strength. At the highest load level considerably high compressive residual were generated in S960Q whereas this was not observed in S355N. Case three by Vöhringer applies not to this test series which can be explained with the high stress concentration at the location of residual stress measurements. Stress increase at the weld toe led to higher plasticity effects than in case of buttwelded samples.

Cyclic loading led to residual stress relaxation both of initial tensile and compressive residual stresses. The residual stress relaxation at comparable load levels was higher than in case of static loading. This is explained by the same effects as mentioned for butt-welded joints. Samples of S960Q generally showed higher residual stress stability which is caused by the very low level of initial residual stresses. Post-weld treated samples did not show different behavior in terms of residual stress relaxation than as-welded samples. Plasticity effects leading to residual stress relaxation are higher at higher levels of residual and load stresses. 

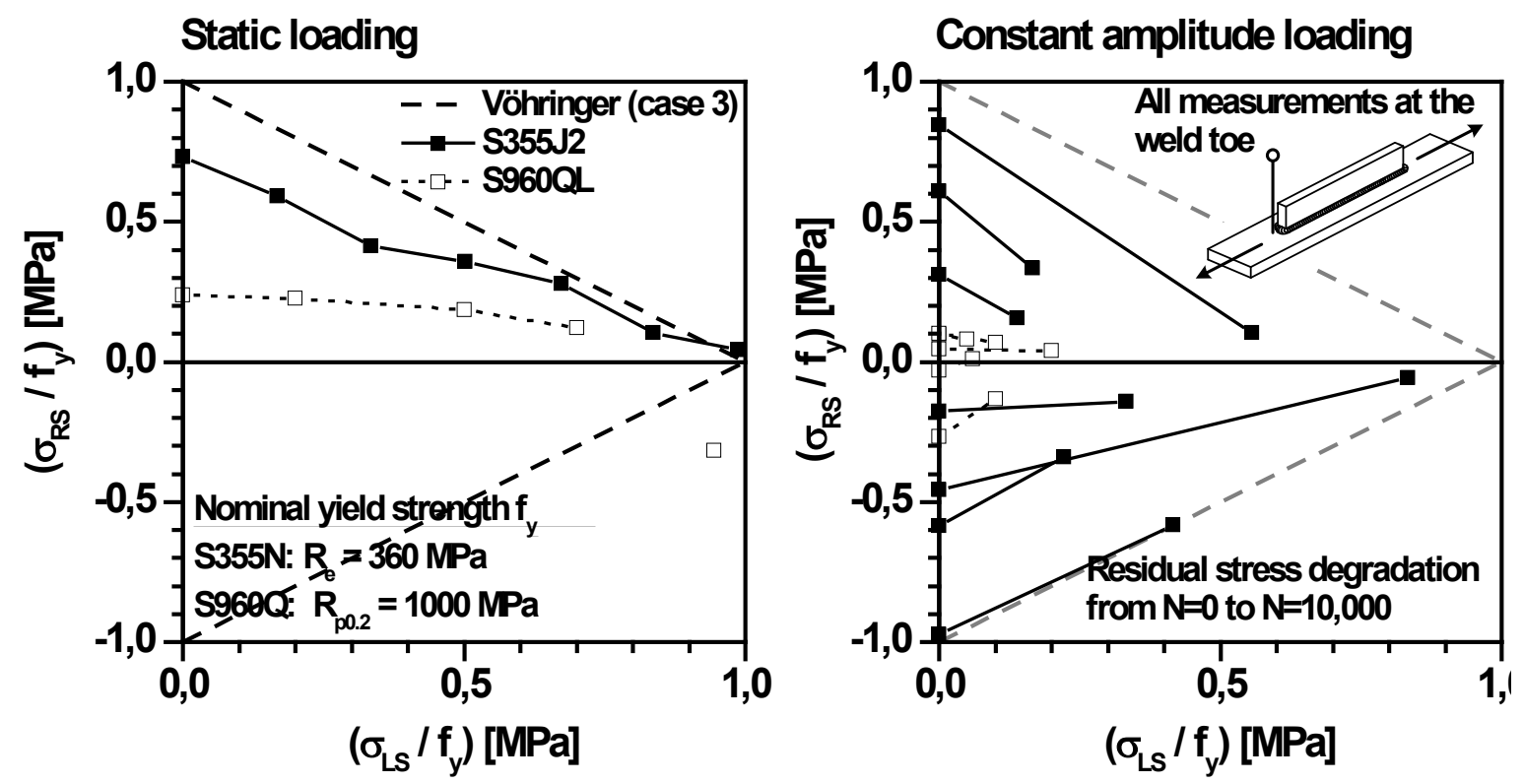

Fig. 5 Static and cyclic residual stress relaxation at the weld toe of fillet-welded longitudinal stiffeners. Nominal load stresses $\sigma_{L S}$ reflect the maximum applied stress of the same sign as the initial residual stresses in the net section (in case of cyclic loading: Mean stress plus stress amplitude (tensile initial residual stresses) respectively mean stress minus stress amplitude (compressive initial residual stresses))

\section{Engineering model}

The authors propose an engineering model for the estimation of residual stress relaxation based on the experimental data, Fig. 6. This model reflects the demonstrated effects of cyclic loading on the residual stresses at the weld notch for butt-welded and fillet welded steels. The stabilized residual stresses $\sigma_{R S, N=10,000}$ can be estimated based on the yield strength of the material $f_{y}$, the initial residual stresses $\sigma_{R S, N=0}$ and the highest load stresses $\sigma_{L S}$. The highest load stresses $\sigma_{L S}$ reflect the maximum and minimum stress during fatigue loading depending on the sign of the initial residual stresses (tensile residual stresses: $\sigma_{L S}=\sigma_{\max }$; compressive residual stresses: $\sigma_{L S=} \sigma_{\min }$ ), Eq. 1 .

$$
\frac{\sigma_{R S, N=10,000}}{f_{y}}=-\frac{\sigma_{R S, N=0}}{f_{y}} \cdot\left|\frac{\sigma_{L S}}{f_{y}}\right|+\frac{\sigma_{R S, N=0}}{f_{y}} .
$$

This approach is based on Vöhringer's case four. It is assumed that cyclic softening leads to residual stress degradation depending on the magnitude of the initial residual stresses. Residual stresses are degraded fully at load levels as high as the static yield strength of the metal. Low residual stresses are predicted to be more stable under mechanical loading.

This model is designed to over-predict stabilized residual stresses on purpose. The reason for this is that mainly tensile residual stresses are of interest for structural engineers. In this matter, overpredicted tensile residual stresses are conservative for the fatigue design. However, this model is not capable of predicting the generation of residual stresses due to local high strains as could be seen in case of longitudinal stiffeners made of S960Q. Further it should not be used without proof of correctness in general and more specific for the prediction of compressive residual stress relaxation. 


\section{Outlook}

This model was derived and tested for the fatigue life prediction of welded longitudinal stiffeners (more on this can be found here [9]). It has shown that the prediction of stabilized residual stresses can be used to correct for the effective stress ratio under consideration of residual stresses and load mean stresses The application of the bonus factor concept according to IIW-recommendations and thus the entire fatigue design becomes now more effective since the bonus factor is no longer depending on the subjective judgment of the residual stress state. It becomes rather possible to account quantitatively for the stabilized residual stresses.

\section{Acknowledgements}

The authors thank the German Research Foundation (DFG) for funding. This work was part of the TP-G2 of the DFG-AIF research cluster IBESS (Integrale Bruchmechanische Ermittlung der Schwingfestigkeit von Schweißverbindungen).

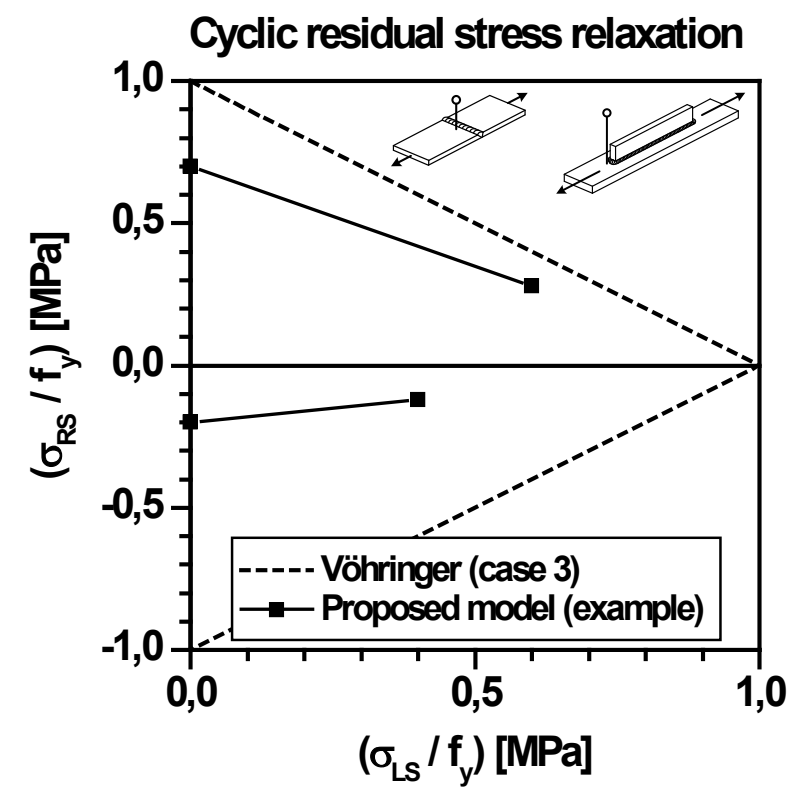

Fig. 6 Proposed model for estimation of stabilized residual stresses in welds

\section{References}

[1] A. Hobbacher, Recommendations for Fatigue Design of Welded Joints and Components, New York: Welding Research Council, 2009.

[2] DIN EN 1993-1 Eurocode 3: Bemessung und Konstruktion von Stahlbauten, Berlin: Beuth Verlag, 2010.

[3] T. Gurney, Fatigue of Welded Structures, London: Cambridge University Press, 1968.

[4] H. Wohlfahrt, "Einfluss von Eigenspannungen und Mittelspannungen auf die Dauerschwingfestigkeit," in Dauerfestigkeit und Zeitfestigkeit, VDI-Bericht 661, Düsseldorf, VDI-Verlag, 1988, pp. 99-127.

[5] O. Vöhringer and H. Wohlfahrt, "Abbau von Eigenspannungen," in Eigenspannungen Entstehung-Messung-Bewertung, Oberursel, DGM-Informationsgesellschaft, 1983, pp. 144156.

[6] T. Nitschke-Pagel, Eigenspannungen und Schwingfestigkeitsverhalten geschweißter Feinkornbaustähle. Dissertation TU Braunschweig, Clausthal-Zellerfeld: Papierflieger, 1995.

[7] H. Wohlfahrt, "Zum Eigenspannungsabbau bei der Schwingbeanspruchung von Stählen," Härtereitechnische Mitteilungen, no. 28, pp. 288-293, 1973.

[8] M. Farajian, Stability and Relaxation of Welding Residual Stresses. Dissertation TU Braunschweig, Aachen: Shaker Verlag, 2011.

[9] J. Hensel, T. Nitschke-Pagel and K. Dilger, "XIII-2642-16: Engineering model for the quantitative consideration of residual stresses in fatigue design of welded components," in IIW-Annual Assambly, Melbourne, 2016. 